Cite this: J. Mater. Chem. A, 2013, 1, 9138

Received 23rd April 2013

Accepted 4th June 2013

DOI: $10.1039 / \mathrm{c} 3 \operatorname{ta} 11611 \mathrm{e}$

www.rsc.org/MaterialsA
View Article Online

View Journal I View Issue

\title{
Improved nanoindentation and microwave shielding properties of modified MWCNT reinforced polyurethane composites
}

\author{
Tejendra K. Gupta, ${ }^{a}$ Bhanu P. Singh, ${ }^{\text {a }}$ Sanjay R. Dhakate, ${ }^{a}$ Vidya N. Singh ${ }^{\text {b }}$ \\ and Rakesh B. Mathur ${ }^{\star a}$
}

Acid modified multiwalled carbon nanotubes (a-MWCNT) reinforced polyurethane (PU) composite films have been fabricated using a solvent casting technique with $0-10 \mathrm{wt} \%$ of a-MWCNTs. A nanoindentation study has been carried out on these films in order to investigate the mechanical properties. Incorporation of a-MWCNTs in a PU matrix led to a drastic increase in the hardness and elastic modulus. The maximum nanoindentation hardness of 217.5 MPa for $10 \mathrm{wt} \%$ a-MWCNT loading was observed as compared to 58.5 MPa for pure PU (an overall improvement of 271\%). The nanoindentation elastic modulus for a 10 wt\% a-MWCNT loaded sample was 1504.2 MPa as compared to $385.7 \mathrm{MPa}$ for pure PU (an overall improvement of 290\%). In addition to hardness and elastic modulus, other mechanical properties i.e. plastic index parameter, elastic recovery, ratio of residual displacement after load removal and displacement at the maximum load and plastic deformation energy have also been investigated. The enhancement in the mechanical properties was correlated with spectroscopic and microscopic investigations using Raman spectroscopy, SEM and TEM. Dispersion of a-MWCNTs in the PU matrix was studied using Raman mapping. Besides the improvement in mechanical properties, the electromagnetic interference shielding properties were also investigated in the $8.2-12.4 \mathrm{GHz}$ (X-band) frequency range. A value of $\sim 29 \mathrm{~dB}$ for the $10 \mathrm{wt} \%$ MWCNT loaded sample having a thickness of $1.5 \mathrm{~mm}$ was obtained. Therefore, these polyurethane composite films shall not only be useful for hard and scratchless coatings but also for protection from electromagnetic radiation in making electromagnetic shielding bags for packaging of electronic circuits and for scratchless tape for laminating circuit boards.

\section{Introduction}

Electromagnetic interference (EMI) has become a serious cause of concern for modern society due to the increased number of electrical and electronic industries. EMI not only causes operational break down of electronic instruments but also harmful for human health. ${ }^{1}$ Many diseases such as leukemia, miscarriages, and breast cancer are associated with continued exposure to electromagnetic pulses. ${ }^{\mathbf{1}, 2}$ In order to save society from these harmful radiation, effective shielding from unwanted electromagnetic waves is needed. In the past, various shielding materials have been used. Conventional metals were the first choice for industry until the last few decades. Electrically conducting polymer composites have gained popularity recently because of their light weight, resistance to corrosion, flexibility,

\footnotetext{
${ }^{a}$ Physics and Engineering of Carbon, Division of Materials Physics and Engineering, CSIR-National Physical Laboratory, New Delhi, 110012, India. E-mail: bps@mail. nplindia.org; rbmathur@mail.nplindia.org; Fax: +91-11-45609310; Tel: +91-1145608460

${ }^{b}$ Electron and Ion Microscopy Section, CSIR-National Physical Laboratory, New Delhi, 110012, India
}

and simpler processing methods. ${ }^{3-5}$ EMI shielding effectiveness (SE) of a composite material depends mainly on the filler's intrinsic conductivity, dielectric constant and aspect ratio., Carbon nanotubes (CNTs) have very high conductivity, small diameter, high aspect ratio and superior mechanical properties which make them an excellent choice to be used as conducting filler in the polymer composites for high performance EMI shielding. ${ }^{3}$ Recently, several studies have been reported on the EMI shielding properties of CNT-polymer composites. ${ }^{3,4,7-20}$ EMI shielding in the $8.2-12.4 \mathrm{GHz}$ (X-band) range is very important for military and commercial applications. Doppler, weather radar, TV picture transmission, and telephone microwave relay systems operate in this frequency range. ${ }^{\mathbf{1 1}}$

Polyurethane (PU) is one of the most versatile materials. ${ }^{21-23}$ It is widely used in coatings, adhesives, thermoplastic elastomers and composites. PU generally consists of a hard segment which is composed of alternating diisocyanate and chain extender molecules (i.e., diol or diamine) and a soft segment which is composed of a linear, long chain diol. ${ }^{24}$ The most important feature of PU's structure is microphase separation arising from the thermodynamic incompatibility of hard and soft segments. 
Very few studies have been reported on CNT reinforced PU composites for their electrical conductivity and EMI shielding properties. Zunfeng et al. ${ }^{3}$ reported the EMI shielding properties of single walled carbon nanotubes (SWCNTs)/polyurethane composite films prepared by simple physical mixing. The shielding effectiveness of $\sim 17 \mathrm{~dB}$ at $20 \mathrm{wt} \%$ of SWCNT loading was achieved in their case. In another study by Zunfeng et al. ${ }^{25}$ the microwave absorption properties in the $2-18 \mathrm{GHz}$ range with $0-25$ wt\% SWCNT loading were investigated and the maximum EMI shielding effectiveness of $22 \mathrm{~dB}$ at $5 \mathrm{wt} \%$ loading was reported. Hoang ${ }^{26}$ reported the EMI shielding effectiveness of MWCNTs-polyurethane composite films in the 8-12 GHz frequency range and the EMI shielding effectiveness of $20 \mathrm{~dB}$ was reported with $22 \mathrm{wt} \%$ MWCNT loading. It is observed from the above studies on CNT-PU composites that shielding effectiveness varies from 17 to $22 \mathrm{~dB}$ at very high loading.

Moreover, these studies do not discuss the mechanical properties of composites except our own studies on EMI shielding properties of MWCNT-PMMA and MWCNT-PS composites and MWCNT-epoxy composites. ${ }^{\mathbf{1 3} 19}$ In addition to the electrical and EMI shielding properties, CNTs improve the mechanical properties of polymeric materials.

Nanoindentation ${ }^{27}$ is a very advanced technique for studying the mechanical properties of polymer composite films such as hardness and elastic modulus due to its ability to measure the loading-unloading response with very high precision. The hardness $(H)$ is defined as the ratio of maximum load applied in the loading process to the projection area created (where maximum load is applied).

To the best of our knowledge, there is only one study, by Kucerová et al. ${ }^{28}$ reporting the mechanical properties of solvent cast films of different carbon materials (carbon microparticles, carbon microfibers and carbon nanotubes) reinforced polyurethane using the nanoindentation test, and the hardness and elastic modulus at $1 \mathrm{mN}$ to $1 \mathrm{~N}$ indentation load was reported. In their studies, in the case of CNTs (non-functionalized), the hardness increased 1.4 times compared to the pure polyurethane matrix. It is known that functionalized CNTs can make better bonding with the polymer matrix and therefore the mechanical properties can improve. There is further scope to study the mechanical and EMI shielding properties of functionalized CNT based polyurethane composites.

Therefore, in this study, acid functionalized MWCNTs (a-MWCNTs) were reinforced in the polyurethane matrix to study the mechanical, electrical and EMI shielding properties of CNT-polyurethane composite films. We also explored the effect of different weight\% of a-MWCNT loading on the various mechanical parameters of the films. The mechanical parameters estimated in the present study are: hardness $(H)$, elastic modulus $(E)$, plastic index parameter $(H / E)$, elastic recovery (ER), load displacement curve, ratio between residual displacement after load removal and displacement at maximum load $\left(h_{\text {res }} / h_{\text {max }}\right)$ and plastic deformation energy. These mechanical properties were also correlated with the results of SEM, TEM and Raman studies. The EMI shielding effectiveness of these films has also been studied.

\section{Experimental}

\subsection{Materials}

A pure polyurethane resin thermoplastic LPR5725EG grade was purchased from C.O.I.M. LARIPUR with a specific gravity of $1.23 \mathrm{gm} \mathrm{cm}^{-3}$ and a softening point of $138^{\circ} \mathrm{C}$. MWCNTs were synthesized using toluene as a carbon source and ferrocene as a catalyst precursor in an in-house built CVD set-up. ${ }^{29}$ The MWCNTs produced were 10-70 $\mathrm{nm}$ in diameter and had an average bundle length of $\sim 300 \mu \mathrm{m}$. These were $90 \%$ pure with $10 \mathrm{wt} \%$ of the Fe catalyst.

\subsection{Modification of MWCNTs}

As-produced MWCNTs were treated with $69 \%$ (v/v) $\mathrm{HNO}_{3}$ for $48 \mathrm{~h}$ in a reflux apparatus ${ }^{\mathbf{3 0 , 3 1}}$ under constant magnetic stirring to convert the MWCNTs to acid functionalized MWCNTs. Hereafter, these will be designated as a-MWCNTs. The treated material was washed several times with deionized water until it was of neutral $\mathrm{pH}$ and dried in a vacuum oven at $100{ }^{\circ} \mathrm{C}$ for $12 \mathrm{~h}$.

\subsection{Fabrication of a-MWCNT-PU composites}

Composite films with different MWCNT loadings i.e. 1, 3, 5 and $10 \mathrm{wt} \%$ in PU were prepared by the solvent casting technique as shown in Scheme 1 and hereafter will be designated as PCNT1, PCNT3, PCNT5, and PCNT10, respectively. A pure PU sample (0\% a-MWCNTs) was also prepared for comparison and will be designated as PCNT0. Initially PU granules were dissolved in DMF under magnetic stirring for $6 \mathrm{~h}$ and a-MWCNTs were dispersed in another beaker in DMF for $6 \mathrm{~h}$ under ultrasonication. The dispersed a-MWCNTs and dissolved PU in DMF were mixed together thoroughly under magnetic stirring for another $6 \mathrm{~h}$. The mixed solution was then poured into a petri dish of size $14.5 \mathrm{~cm}$ and placed in a vacuum oven at $80^{\circ} \mathrm{C}$ for $12 \mathrm{~h}$ in order to evaporate the solvent. A flat film $(\sim 1.5 \mathrm{~mm}$ thickness) of PU-MWCNT was taken out from the petri dish and the sample was cut to the desired size for various measurements.

\subsection{Characterization}

The morphologies of MWCNT and MWCNT-PU composite films were investigated by SEM (Leo 440S, UK) and HRTEM (Technai G20-stwin, $300 \mathrm{kV}$ instrument). The analysis of the functional groups attached to the MWCNTs was studied by FTIR (NICOLET 5700) techniques. Raman studies of the a-MWCNTs and a-MWCNT-PU composite films were carried out using a Renishaw inVia Raman spectrometer, UK, with an excitation source of $785 \mathrm{~nm}$. The nanoindentation study was carried out using an IBIS-Nanoindentation (M/S Fisher-Cripps Laboratories Pvt. Limited, Australia) system equipped with a Berkovich indenter and the other details are given elsewhere. ${ }^{32}$ The electrical conductivity of the composite films were measured by a four-point probe method $^{17,31}$ using a Keithley 224 programmable current source and a 197A auto ranging digital microvoltmeter. The values reported in text are an average of at least five readings of voltage drop at different positions of the sample. EMI shielding effectiveness (SE) was measured by 


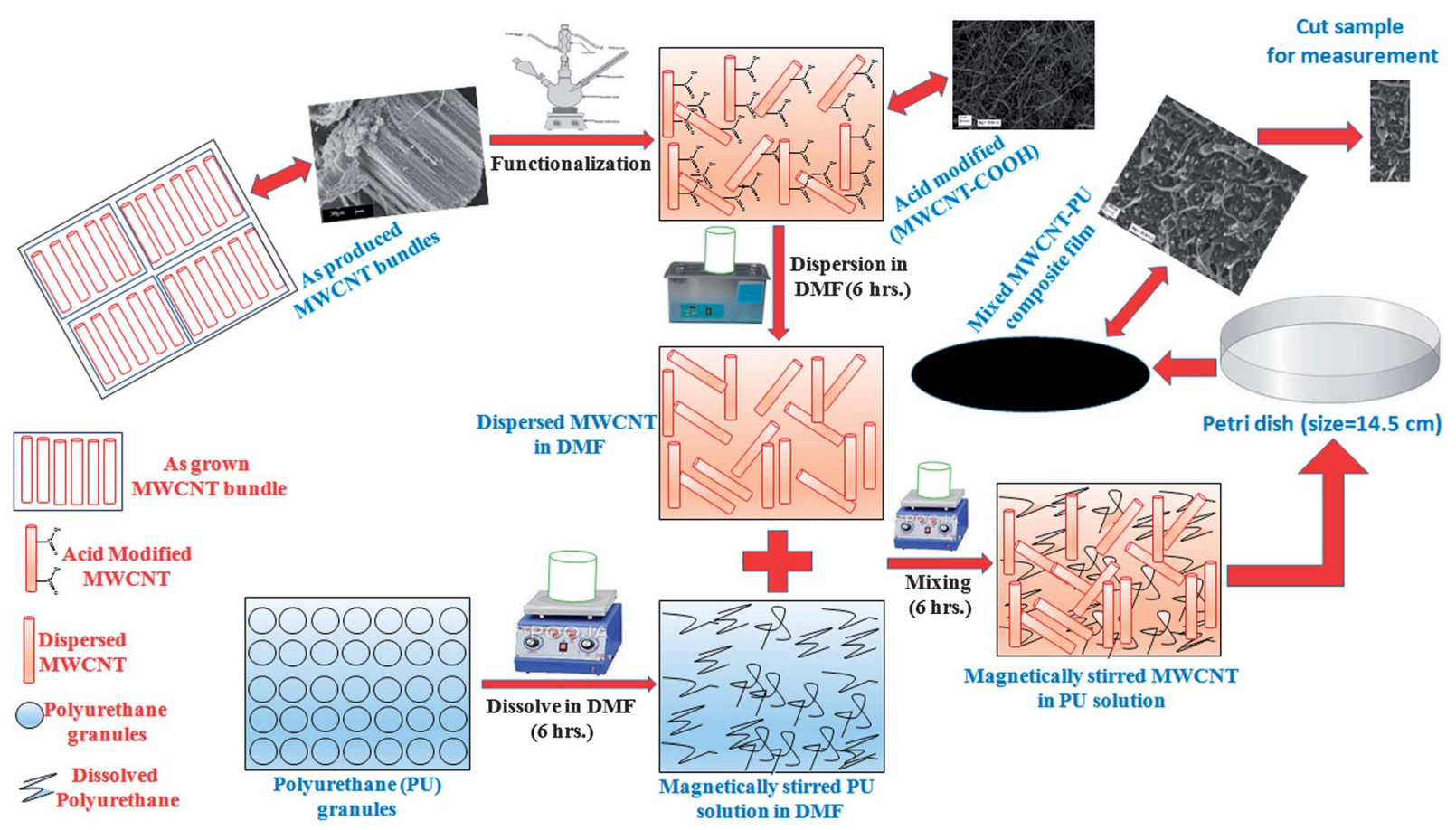

Scheme 1 Process for the fabrication of the composite.

placing rectangular pellets $(1.5 \mathrm{~mm}$ thick) inside the X-band (8.2-12.4 GHz) waveguides using a vector network analyzer (VNA E8263B Agilent Technologies).

In order to prepare the samples for TEM studies, films were ground to make them thin $(\sim 200 \mu \mathrm{m})$. A circular slice of $2.3 \mathrm{~mm}$ is cut using an ultrasonic cutter. The slice is polished and dimple ground to make it electron transparent $(\sim 50 \mathrm{~nm}$ at centre) and TEM studies were carried out using a Technai G20, 300 kV FEG microscope.

\section{Results and discussion}

\subsection{Characteristics of MWCNTs}

Fig. 1(a) shows the SEM micrograph of as-produced MWCNTs in the form of aligned bundles and Fig. 1(b) shows the SEM micrograph of individual MWCNTs after dispersion in DMF. Fig. 1(c) and (d) show the SEM images of MWCNTs after functionalization at low and high magnifications, respectively. Fig. 1(e) shows the TEM image of the as-produced MWCNT which reveals the presence of metallic impurities in the cavity and at the tip of the MWCNTs. The TEM micrograph shows that the surface of the MWCNTs is smooth while the TEM image of a-MWCNTs (Fig. 1(f)) does not show any metallic impurities and their surface is very rough and defective which was generated during functionalization. This confirms the presence of functional groups at the surface of MWCNTs. These defects help in the chemical bonding between CNT and PU.

The liquid phase oxidation of MWCNTs modified the surface structure of CNTs. Several functional groups such as the carboxylic group $(-\mathrm{COOH})$, the carbonyl group $(-\mathrm{C}=\mathrm{O})$ and the hydroxyl group $(-\mathrm{OH})$ were generated. Fig. $1(\mathrm{~g})$ shows the comparison of the FTIR spectra of CNTs before and after oxidation with concentrated nitric acid $\left(\mathrm{HNO}_{3}\right)$. FTIR spectra of as-produced MWCNTs show peaks at $1640 \mathrm{~cm}^{-1}$ and $1020 \mathrm{~cm}^{-1}$ which are due to the $\mathrm{C}=\mathrm{C}$ and $\mathrm{C}-\mathrm{C}$ bonds, respectively. Carboxylic groups on the surfaces of as-produced MWCNTs could be due to the oxidation of the MWCNT surface during functionalization. This is evident as the peak at $1740 \mathrm{~cm}^{-1}$ is associated with the stretching mode of carbonyl groups $(-\mathrm{C}=\mathrm{O})$. The peak at $3450 \mathrm{~cm}^{-1}$, can be assigned to the $\mathrm{O}-\mathrm{H}$ stretching from carboxylic groups $(\mathrm{O}=\mathrm{C}-\mathrm{OH})$, while the peaks at 2920 $\mathrm{cm}^{-1}, 2850 \mathrm{~cm}^{-1}$ and $1375 \mathrm{~cm}^{-1}$ can be assigned to $-\mathrm{CH}_{2}$ antisymmetric stretching, $\mathrm{CH}_{3}$ symmetric stretching and $-\mathrm{CH}_{3}$ symmetric bending vibrations, respectively.

\subsection{Mechanical properties determined using nanoindentation}

The nanoindenter is an important tool to study the mechanical properties of thin films. It provides information on various mechanical properties like hardness $(H)$, elastic modulus $(E)$, elastic recovery (\%ER) and load displacement curves. The load versus displacement curves at a minimum indentation load of $1 \mathrm{mN}$ for the PCNT0, PCNT1, PCNT3, PCNT5 and PCNT10 films have been studied and are shown in Fig. 2(a-e), respectively. The mark of the indenter in the composite film of PCNT10 is shown in the SEM image (Fig. 2(f)). Load versus displacement curves are further used to estimate the several other elastic and plastic properties of these films. It has been reported in the previous study that indentation hardness and other related mechanical properties depend on the substrate and nature of the film. ${ }^{33}$ In the present study, self-supporting free standing 

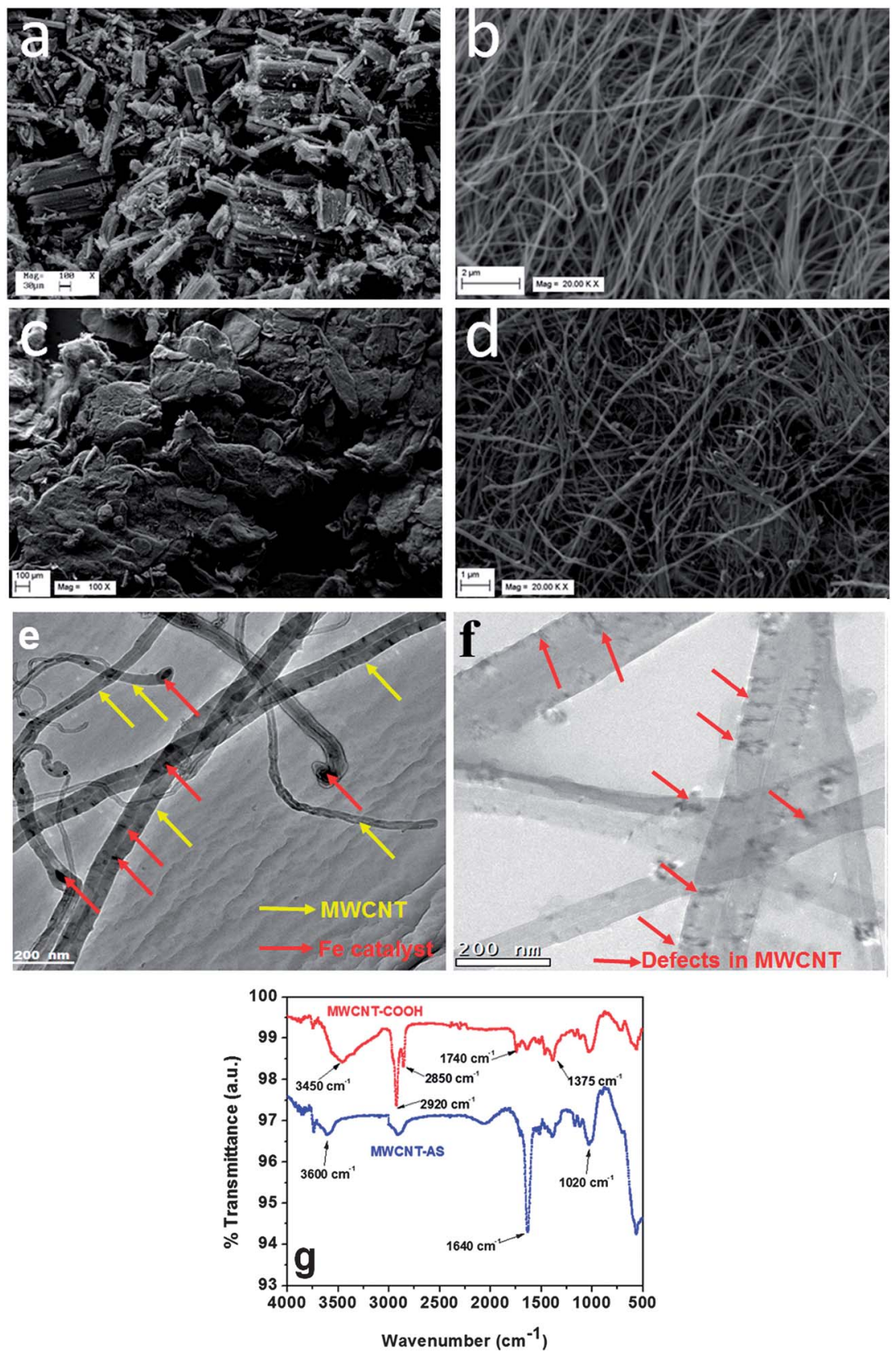

Fig. 1 SEM micrograph of (a) as-produced MWCNT in a bundled form, (b) as-produced MWCNT dispersed in DMF, (c) a-MWCNT at low magnification, (d) a-MWCNT at high magnification. TEM micrograph of (e) as-produced MWCNT, (f) a-MWCNT and (g) FTIR spectra of as-produced MWCNT and a-MWCNT, respectively.

a-MWCNT-PU films have been prepared which avoid the substrate effect on the mechanical properties.

The variation of $H$ at $1 \mathrm{mN}$ load is shown in Fig. 3 (calculated by the relationship given in eqn $\left.(1)^{27}\right)$

$$
\text { Hardness }(H)=\frac{P_{\max }}{A_{\mathrm{r}}}
$$

where $P_{\max }$ is the maximum load and $A_{\mathrm{r}}$ is the residual projected area of contact between the indenter and the specimen. For an indenter of pre-known geometry, the projected area can be calculated with the help of contact depth $\left(h_{\mathrm{c}}\right)^{34}$

$$
A_{\mathrm{r}}=24.5 h_{\mathrm{c}}
$$

where $h_{\mathrm{c}}$ is the measured contact depth.
Contact depth can be calculated with the help of load value, stiffness, maximum depth and indenter geometry as

$$
h_{\mathrm{c}}=h_{\max }-\varepsilon \frac{P_{\max }}{S}
$$

where $h_{\max }$ is the maximum depth, $\varepsilon$ is a constant well defined for a particular type of indenter and its value is 0.75 in the case of the Berkovich indenter. Stiffness $(S)$ is calculated by the initial linear part of the unloading curve i.e. $\mathrm{d} P / \mathrm{d} h$.

According to the $\mathrm{O}-\mathrm{P}$ model $^{27}$ in the unloading curve, load follows a power law as

$$
P=B\left(h-h_{\mathrm{c}}\right)^{m}
$$

where, $B$ and $m$ are constants determined from the $P-h$ plot. 

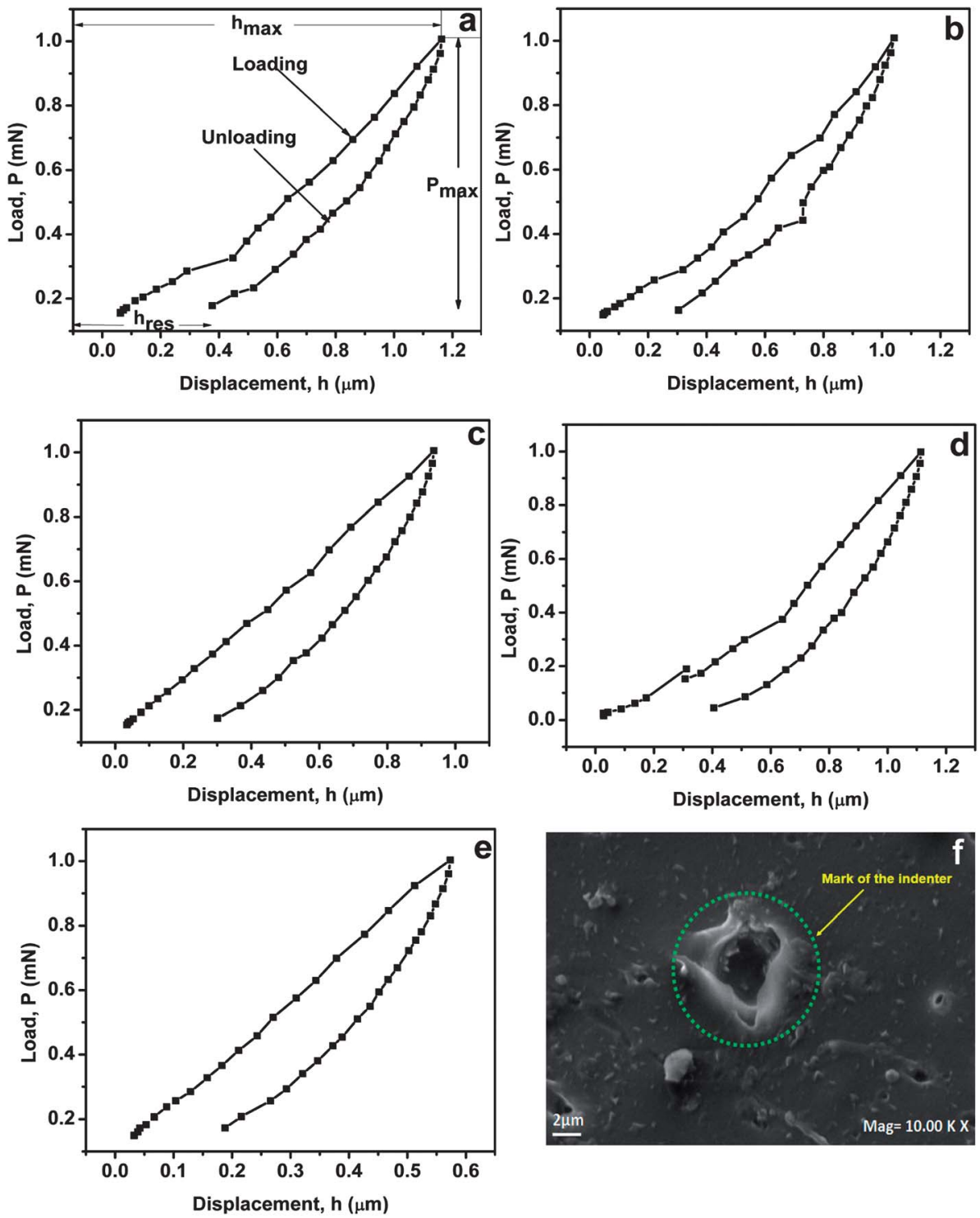

Fig. 2 Load versus displacement curves of (a) PCNTO, (b) PCNT1, (c) PCNT3, (d) PCNT5, (e) PCNT10 at $1 \mathrm{mN}$ load and (f) an SEM micrograph of the mark of the indenter.

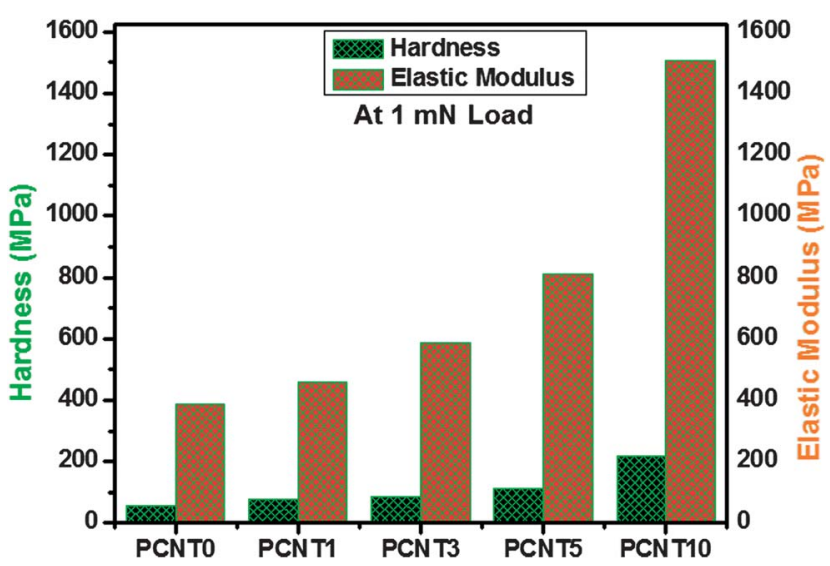

Fig. 3 Variation of hardness and elastic modulus at $1 \mathrm{mN}$ indentation load.
It is observed that the value of hardness increases with the increase in the wt\% of MWCNT. The value of $\mathrm{H}$ for pure PCNT0 is 58.5 MPa and it increased to 217.5 MPa for PCNT10. Similarly, the elastic modulus increased from 385.7 for PCNT0 to 1504.2 MPa for PCNT10. Thus, an overall improvement of $271 \%$ in the hardness and $290 \%$ in the elastic modulus is observed.

This enhancement in the hardness and elastic modulus of MWCNTs reinforced PU composites may be due to the presence of a strong interaction between a-MWCNTs and PU as shown in Scheme 2.

The interaction between CNT and PU is further confirmed by SEM images of the fractured surfaces of a-MWCNT-PU composites as shown in Fig. 4.

The hardness strongly depends on the nano to microstructural defects present in the network and is related to the bonding between the atoms and the ability of the bonds to 


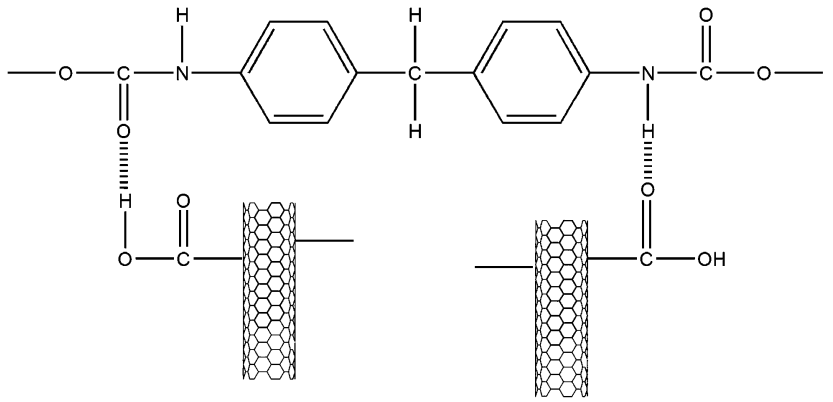

Scheme 2 A possible interaction mechanism of hydrogen bonding between the PU chain and a-MWCNT.

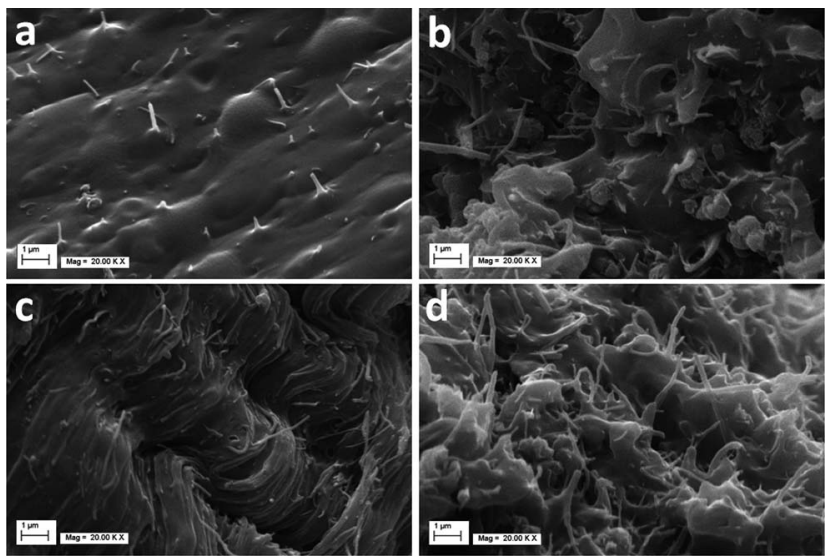

Fig. 4 SEM images of the fractured surface of a-MWCNT-PU composites for (a) PCNT1, (b) PCNT3, (c) PCNT5 and (d) PCNT10.

withstand deformation caused by compression, extension, bending or breaking. ${ }^{33}$ SEM images of the fractured surface of the a-MWCNT-PU composites reveal that the interaction
Table 1 Peak allocation in Raman spectra of pure PU

\begin{tabular}{ll}
\hline $\begin{array}{l}\text { Raman } \\
\text { shift }\left(\mathrm{cm}^{-1}\right)\end{array}$ & Band allocation \\
\hline 1704 & $\begin{array}{l}\text { Ester } \nu(\mathrm{C}=\mathrm{O}), \text { urethane } \\
\text { amide } \mathrm{I} \nu(\mathrm{C}=\mathrm{O}) \\
\end{array}$ \\
1611 & $\nu(\mathrm{Ar})$ \\
1539 & $\nu_{\text {sym. }}(\mathrm{N}=\mathrm{C}=\mathrm{O})$ \\
1446 & Urethane amide III $\nu(\mathrm{C}=\mathrm{O})$ \\
1304 &
\end{tabular}

between CNTs and the PU matrix increases with the increase in CNT loading (Fig. 4(a-d)). This is due to an increase in interaction volumes which enhances the hardness of the polymer films with the increase in the amount of a-MWCNTs. In order to further investigate the interaction and bonding between a-MWCNTs and PU composite films, Raman spectroscopic analysis has been carried out for a-MWCNT, PU and a-MWCNTPU composite films. The results are interpreted based on changes in the Raman shift as shown in Fig. 5. Raman shift can provide insight into dispersion and interaction of a-MWCNTs in the PU matrix. ${ }^{35-37}$

Fig. 5(b) shows the Raman spectrum of PCNT0 and the different bands are listed in Table 1 . The peaks at $1704 \mathrm{~cm}^{-1}$, $1614 \mathrm{~cm}^{-1}, 1539 \mathrm{~cm}^{-1}, 1446 \mathrm{~cm}^{-1}$ and $1304 \mathrm{~cm}^{-1}$ can be assigned to the $\mathrm{N}-\mathrm{H}$ stretching vibrations of urethane amide I, $\mathrm{C}=\mathrm{O}$ stretching vibrations of esters and aromatic rings, $\mathrm{C}-\mathrm{N}$ stretching of urethane amide II, symmetrical stretching vibrations of the $\mathrm{N}=\mathrm{C}=\mathrm{O}$ group and $\mathrm{C}=\mathrm{O}$ stretching of urethane amide III, respectively. ${ }^{38-41}$

After the addition of a-MWCNTs, Raman peaks of pure PU disappear (Fig. 5(a)), which shows that CNTs dominate over PU. The shifting of the G-band peak of a-MWCNT in a-MWCNT-PU
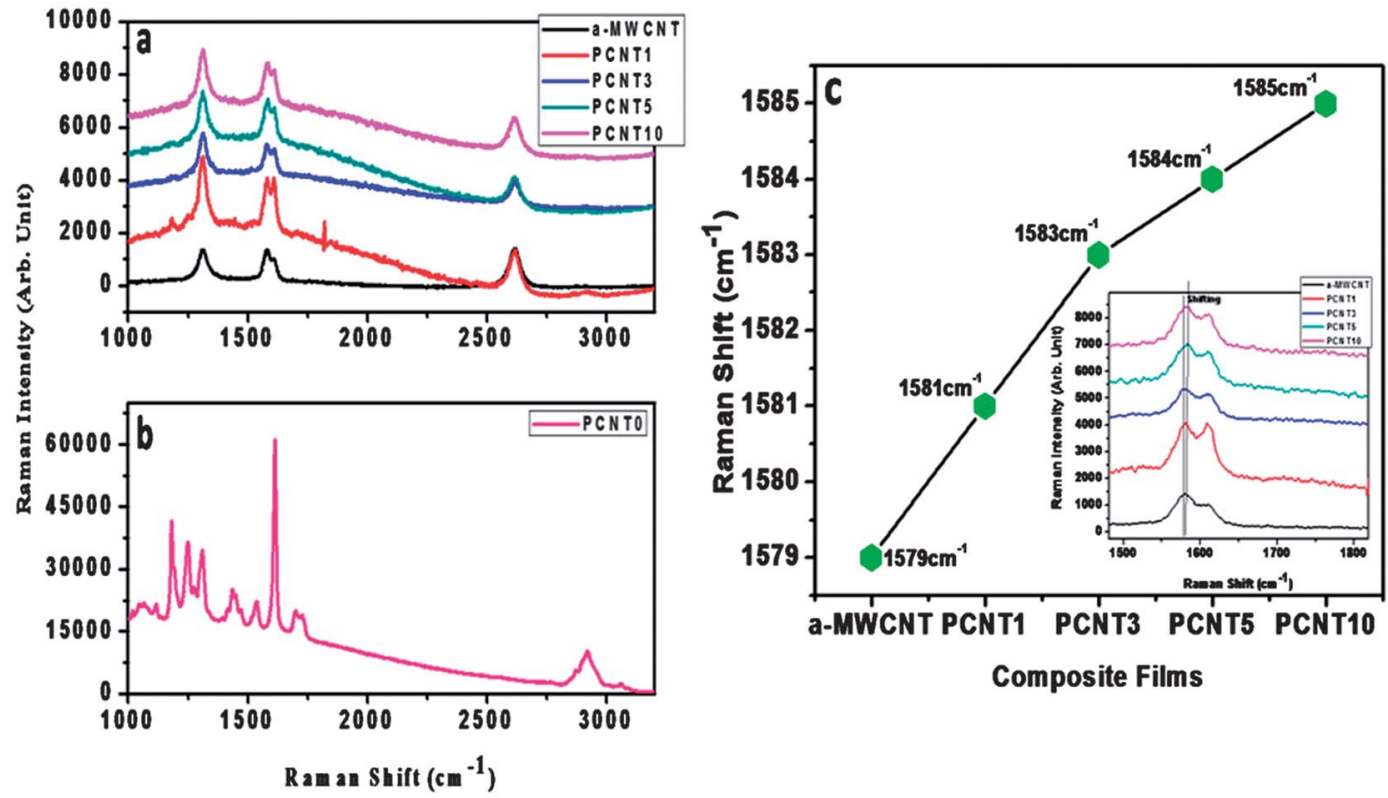

Fig. 5 (a) Raman spectra of a-MWCNT, PCNT1, PCNT3, PCNT5 and PCNT10, (b) Raman spectrum of PCNT0 and (c) variation in the Raman shift of the G-band of different composite films and inset shows the magnified view of the Raman shift. 
composites shows the interaction between a-MWCNT and PU. Fig. 5(c) shows that the band at $1579 \mathrm{~cm}^{-1}$ of a-MWCNTs shifts from 1579-1581 $\mathrm{cm}^{-1}$ in PCNT1 to $1579-1583 \mathrm{~cm}^{-1}$ in PCNT3, $1579-1584 \mathrm{~cm}^{-1}$ in PCNT5 and $1579-1585 \mathrm{~cm}^{-1}$ in PCNT10. The total shift is $6 \mathrm{~cm}^{-1}$ as shown in the inset of Fig. 5(c). This significant increase in the Raman shift shows the good dispersion and interaction between a-MWCNT and the PU matrix.

In order to further confirm the dispersion, Raman mapping was carried out using a Renishaw inVia Raman spectrometer with $785 \mathrm{~nm}$ excitation wavelength. The measurements were carried out in the $50 \times 50 \mu \mathrm{m}$ region with a step size of $5 \mu \mathrm{m}$ in the $x$ and $y$ directions and a laser power of $0.5 \mathrm{~mW}$. The mapping was carried out around the G-band position of a-MWCNT and a-MWCNT-PU composites. The pure PU film was also mapped around the highest peak intensity position of $1614 \mathrm{~cm}^{-1}$. Fig. 6(a-f) show the 3-D contour plots of Raman intensity for a-MWCNT, PCNT0, PCNT1, PCNT3, PCNT5 and PCNT10, respectively. No significant change is observed in Raman intensity throughout the mapped area of all composite films. It is very interesting to note that the contour plot of PCNT10 is almost flat which shows that a-MWCNTs are uniformly dispersed throughout the matrix even at such high loadings. This is the main reason behind the significant improvement in the mechanical properties of the samples.
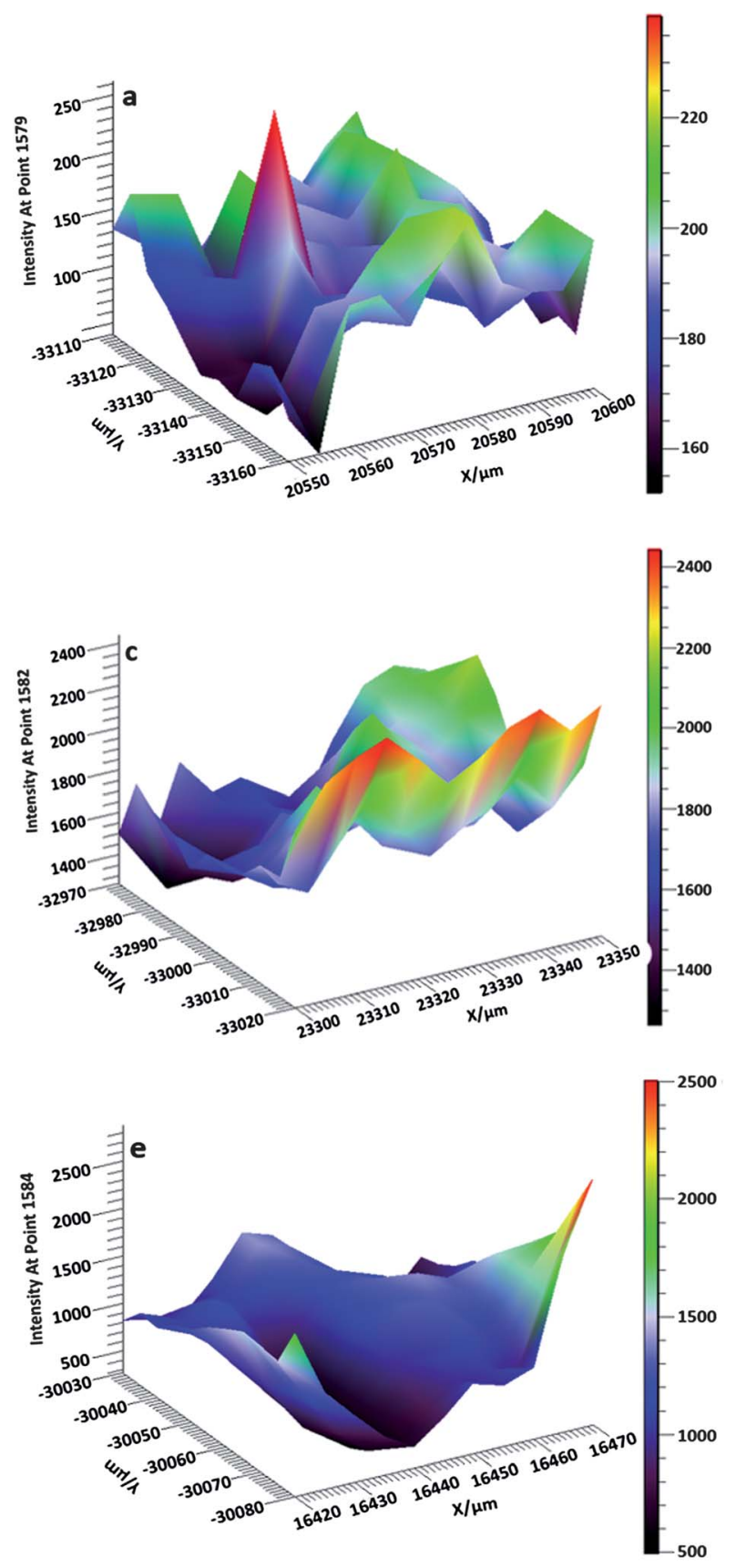
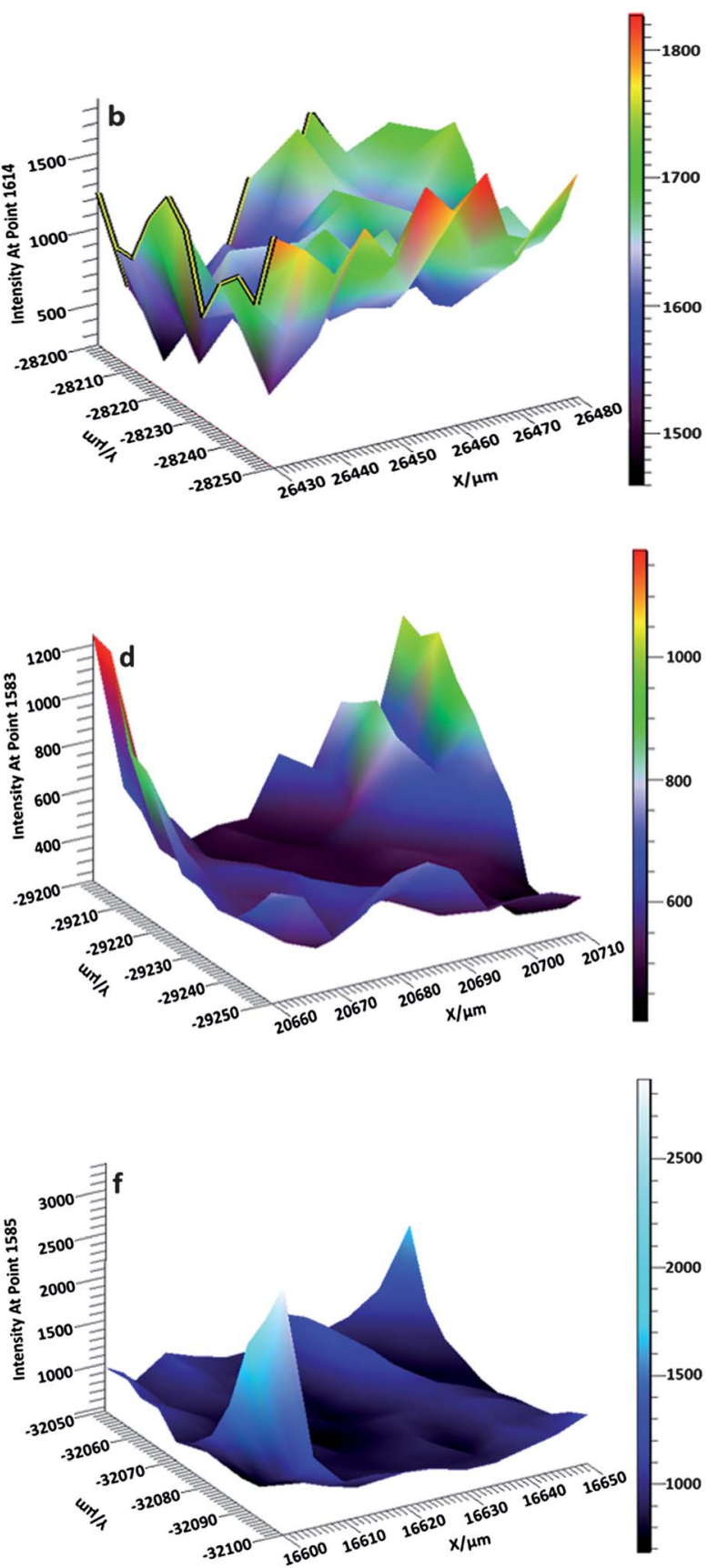

Fig. 6 Raman mapping of (a) a-MWCNT, (b) PCNTO, (c) PCNT1, (d) PCNT3, (e) PCNT5 and (f) PCNT10. 
Fig. 7 shows the TEM micrograph of $10 \mathrm{wt} \%$ a-MWCNT-PU composite films. In Fig. 7(a), CNTs are observed dispersed uniformly in the PU matrix and were seen to be in the PU matrix. Fig. 7(b) shows that the CNT is encapsulated in the polymer matrix and there is a strong interaction at the surface of the CNT and polymer because nanotubes appeared thickly coated.

In addition to hardness and elastic modulus, the wear resistance is also a very important parameter in determining the quality of the composite films. The plastic resistance parameter
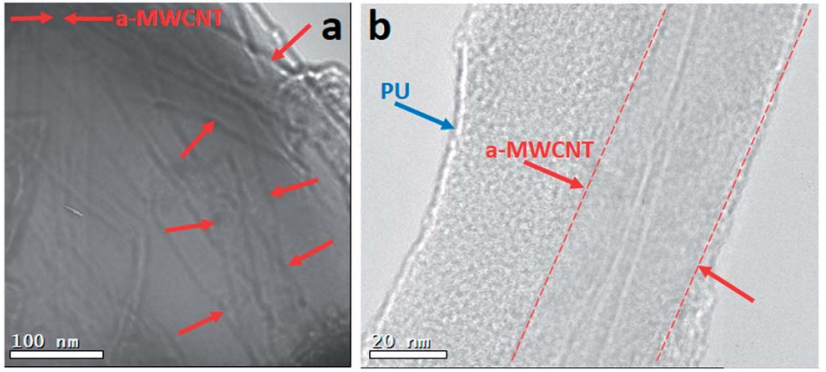

Fig. 7 TEM micrograph of (a) a-MWCNT embedded in the PU matrix for PCNT10, (b) a single a-MWCNT with PU attached around it.

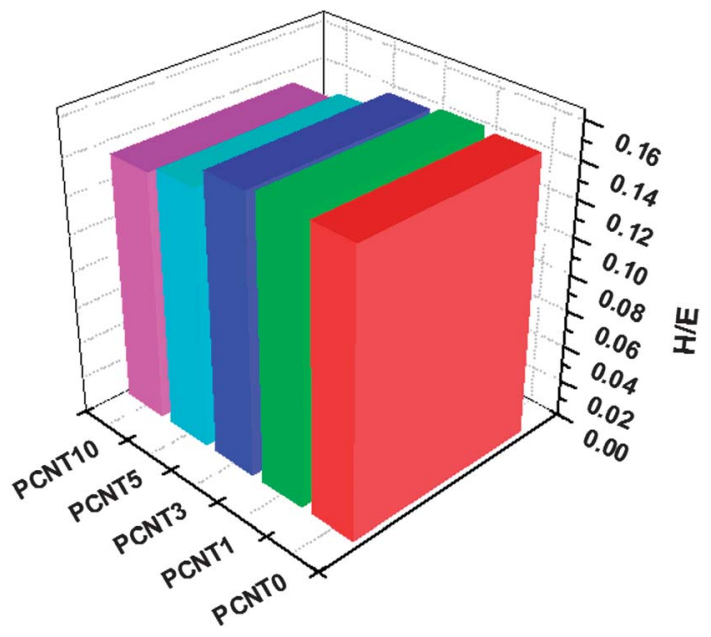

Fig. 8 Plastic resistance parameter $(H / E)$ at $1 \mathrm{mN}$ indentation load.
$(H / E)$ explains not only the elastic-plastic properties but also gives information about wear resistance.

The variation of $H / E$ at $1 \mathrm{mN}$ load for various MWCNT-PU composite films is shown in Fig. 8. The value of $H / E$ is 0.13 for $10 \mathrm{wt} \%$ loading of MWCNT in the PU matrix (PCNT10) and is 0.15 for the pure PU film (PCNT0). The lower value of $H / E$ in the PCNT10 film reveals that a larger fraction of work is consumed in a plastic deformation and the large value of $H / E$ for the PCNT0 film indicates less plastic deformation. Thus, CNT loaded films are better for hard and scratchless coatings.

Load versus displacement curves are used to calculate the elastic recovery (ER). The values of ER were calculated by employing the relationship given in eqn (5).

$$
\% \mathrm{ER}=\frac{h_{\max }-h_{\mathrm{res}}}{h_{\max }} \times 100
$$

where, $h_{\max }$ and $h_{\text {res }}$ are the displacement at the maximum load and residual displacement after load removal, respectively. Since there is a competition between elastic and plastic deformation under the load, the values of ER for different composite films vary in the $63.6-70.2 \%$ range as shown in Fig. 9(a). The soft polymer films show some plastic deformation due to surface penetration by a sharp indenter. The ER results show that there is a slight difference in the PCNT0 and PCNT10 and polymer films recovers after the load removal. The $h_{\text {res }} / h_{\max }$ curves of various composite films are shown in Fig. 9(b). The behavior is similar to that of ER.

The value of this parameter should vary between 0 and 1 in which the lower limit corresponds to the fully elastic behavior and the upper limit corresponds to rigid plastic behavior. Our results vary between 0.160 and 0.175 which indicates the fully elastic behavior of these films at $1 \mathrm{mN}$ load. These observed results are in good agreement with the ER results.

The estimation of contact stiffness $(\mathrm{d} P / \mathrm{d} h)_{\max }$ has been carried out to figure out the elastic and elastic-plastic properties of MWCNT-PU composite films. Stiffness is defined as the resistance of an elastic body to deformation under load. The variation of contact stiffness for composite films is shown in Fig. 10(a). It is evident from the figure that the composite film of PCNT10 exhibits maximum stiffness. The value of stiffness for PCNT0 is $1.45 \times 10^{3} \mathrm{~N} \mathrm{~m}^{-1}$ and it increased to $2.59 \times 10^{3} \mathrm{~N} \mathrm{~m}^{-1}$ for PCNT10. Thus, an overall improvement of $\sim 78 \%$ in stiffness

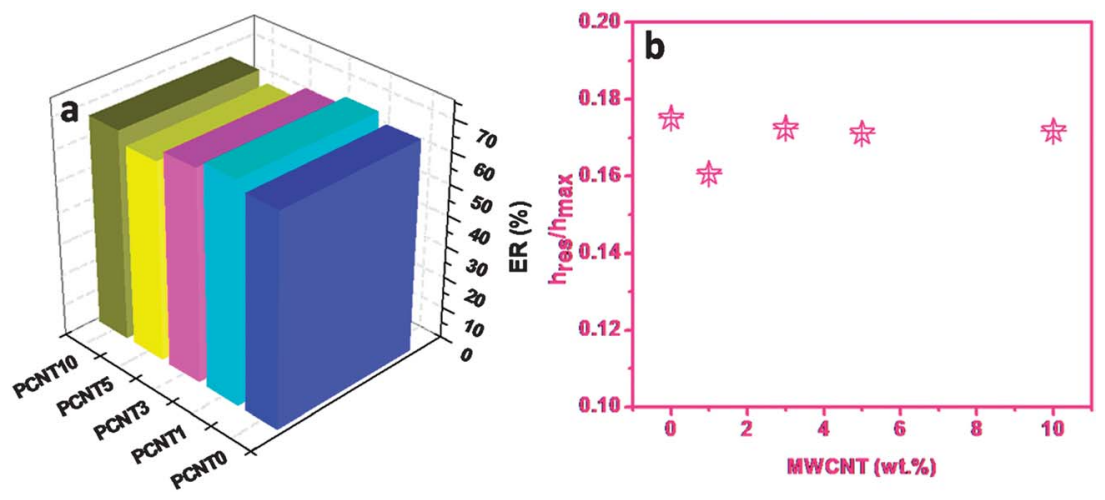

Fig. 9 Variation of (a) \% elastic recovery (\% ER) and (b) $h_{\text {res }} / h_{\max }$ with a-MWCNT loading at $1 \mathrm{mN}$ indentation load. 

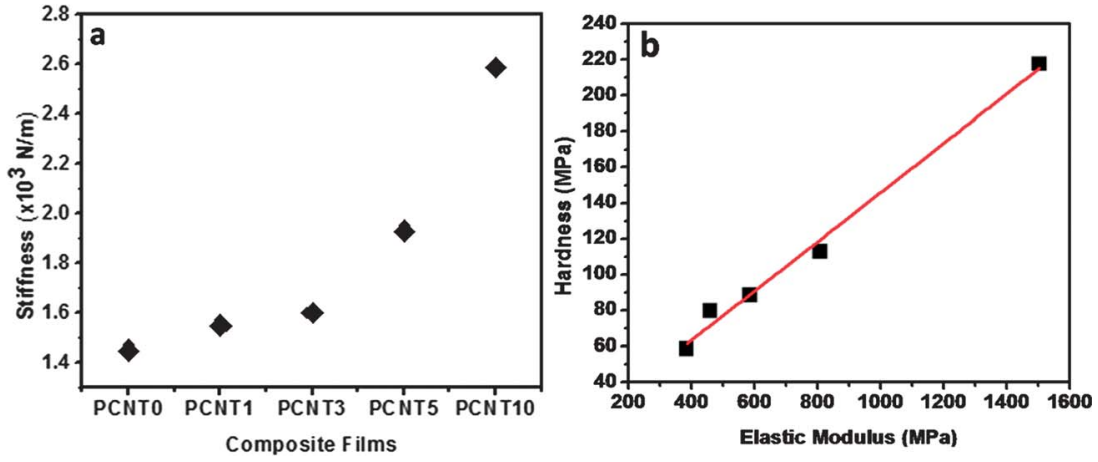

Fig. 10

(a) Variation of stiffness with a-MWCNT loading and (b) linear behavior of the H-E curve for a different type of MWCNT-PU composite films.

is observed. The observed value of stiffness is in good agreement with the results of hardness and elastic modulus.

The $H$ versus $E$ curve for all the PU-MWCNT composite films is shown in Fig. 10(b). Generally, $H$ varies linearly with $E$ according to the relationship given in eqn (6). ${ }^{42}$

$$
H=\frac{1}{10} \times E
$$

In the MWCNT-PU composite films, the $H$ and $E$ follow the linear path from PCNT0 to PCNT10 which indicates toughness of the structure. The theoretical values of $H$ and $E$ are in good agreement with the experimental results.

The elastic and plastic properties of these MWCNT-PU composite films in terms of energy (plastic deformation energy $\left.\left(U_{\mathrm{r}}\right)\right)$ have also been calculated. The deformation energy is calculated by the relationship given in eqn $(7)^{27}$

$$
U_{\mathrm{r}}=\left[\frac{1}{3} \sqrt{\frac{1}{\omega_{0} \tan ^{2} \psi}}\right] \frac{1}{\sqrt{H}} P^{3 / 2}
$$

where $\omega_{0}$ is the geometry constant and attains the value of 1.3 for the pyramidal indenter, $P$ is the load and $\psi$ is the half angle of the Berkovich indenter and has the value of $65.3^{\circ}$. The variation of $U_{\mathrm{r}}$ for different loadings of MWCNT in PU composite films is shown in Fig. 11. It is to be noted from eqn (7) that $U_{\mathrm{r}}$ is inversely proportional to the hardness $(H)$. $U_{\mathrm{r}}$ results follow the said statement. The minimum value of $U_{\mathrm{r}}$ is $2.78 \times 10^{-10} \mathrm{~J}$ at 1 $\mathrm{mN}$ load for PCNT10. The results for $U_{\mathrm{r}}$ are also in good agreement with the results for $H$.

In addition to the good mechanical properties, these composites should have good electrical conductivity due to the extraordinary electrical conductivity of CNTs. Taking this into account, electrical conductivity and EMI shielding in the $\mathrm{X}$-band of these composites have been studied.

\subsection{Electrical conductivity and electromagnetic shielding measurements}

Fig. 12 shows the variation in the room temperature electrical conductivity of a-MWCNT-PU composite films with CNT loading. A sharp increase in the electrical conductivity up to $10 \%$ of MWCNT loading was observed and the value reaches

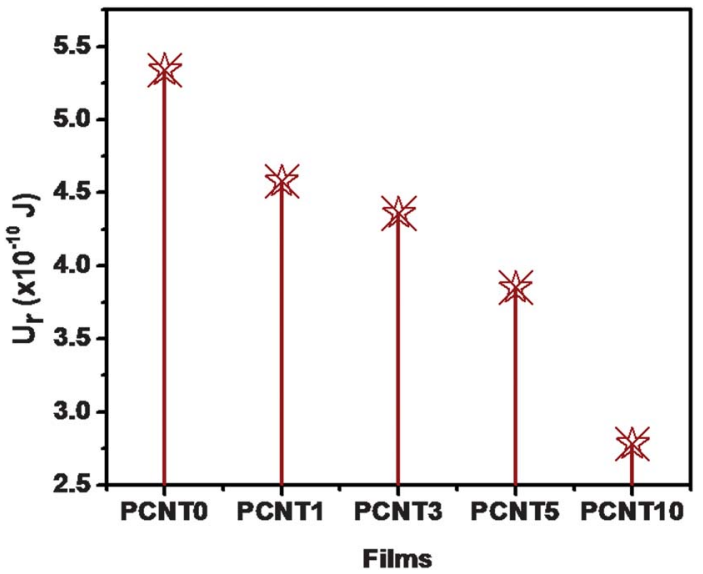

Fig. 11 Deformation energy $\left(U_{r}\right)$ of different MWCNT-PU composite films.

$0.124 \mathrm{~S} \mathrm{~cm}^{-1}$. This may be due to proper formation of the network between PU and CNTs as observed in the SEM images of the fractured surface of a-MWCNT-PU composite films (Fig. 4(a-d)). The good dispersion of these composite films is due to hydrogen bonding between the MWCNT-COOH and PU chains (diisocynates and diols), as shown in Scheme 2, which results in the enhancement of electrical conductivity of the composites. This network forms an extra conducting path and

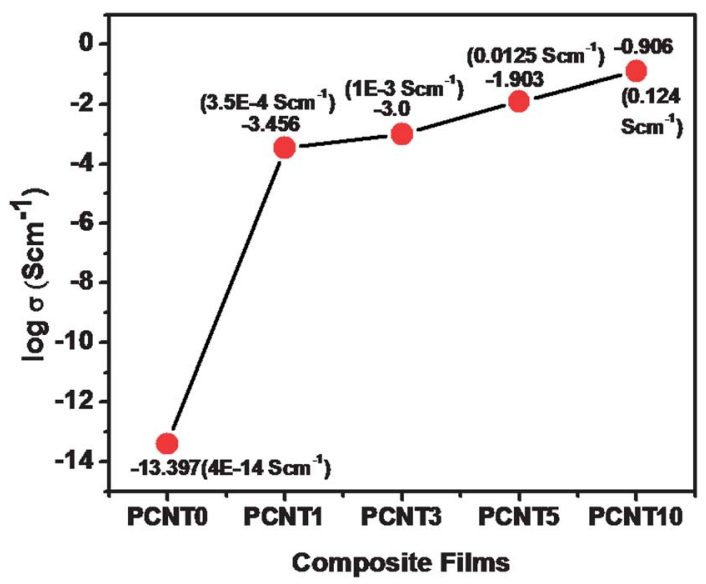

Fig. 12 Log of electrical conductivity curve of MWCNT-PU composite films. 
this increases the number of charge transport paths. The high value of electrical conductivity will be useful for efficient EMI shielding response.

The EMI shielding effectiveness of a material is its ability to attenuate EM radiation which can be expressed in terms of the ratio of incident to transmitted power. ${ }^{19}$ The EMI attenuation offered by a shield depends on three factors: ${ }^{19,43,44}$

(i) absorption of the wave as it passes through the shield's thickness,

(ii) reflection of the wave from the front face of the shield and

(iii) multiple reflections of the waves at various interfaces.

Therefore, the shielding effectiveness of materials is determined by three losses viz. absorption loss $\left(\mathrm{SE}_{\mathrm{A}}\right)$, reflection loss $\left(\mathrm{SE}_{\mathrm{R}}\right)$ and multiple reflection loss $\left(\mathrm{SE}_{\mathrm{M}}\right)$ and can be expressed as

$$
\mathrm{SE}(\mathrm{dB})=\mathrm{SE}_{\mathrm{A}}+\mathrm{SE}_{\mathrm{R}}+\mathrm{SE}_{\mathrm{M}}=10 \log _{10}\left(\frac{P_{\mathrm{t}}}{P_{\mathrm{i}}}\right)
$$

where $P_{\mathrm{t}}$ and $P_{\mathrm{i}}$ are the transmitted and incident power of EM waves, respectively. ${ }^{19}$ As $P_{\mathrm{t}}$ is always less than $P_{\mathrm{i}}$, shielding effectiveness is a negative quantity. A shift towards a more negative value means an increase in the magnitude of shielding effectiveness. When the EMI shielding due to absorption $\left(\mathrm{SE}_{\mathrm{A}}\right)$ of the material is more than $-10 \mathrm{~dB}$, loss due to the multiple reflections $\left(\mathrm{SE}_{\mathrm{M}}\right)$ can be neglected. ${ }^{\mathbf{1 9 4 5}}$ Thus, shielding effectiveness can be expressed as

$$
\mathrm{SE}(\mathrm{dB})=\mathrm{SE}_{\mathrm{A}}+\mathrm{SE}_{\mathrm{R}}
$$

The total shielding effectiveness $\left(\mathrm{SE}_{\mathrm{T}}\right)$ value of the a-MWCNT-PU composite film is shown in Fig. 13a. The results revealed that the pure polyurethane sample is almost transparent towards incident microwave radiation and provides negligible attenuation $\left(\mathrm{SE}_{\mathrm{T}} \sim 0.98 \mathrm{~dB}\right.$ at a mid-frequency of 10.3 GHz).

However, the addition of a-MWCNT results in the systematic improvement of $\mathrm{SE}_{\mathrm{T}}$ and it reached $-29 \mathrm{~dB}$ (>99\% attenuation) for PCNT10. This can be ascribed to the formation of conducting networks throughout the electrically insulating polyurethane matrix. For further investigation of the shielding mechanism, $\mathrm{SE}_{\mathrm{T}}$ for a-MWCNT-PU composites is resolved into the resultant absorption loss $\left(\mathrm{SE}_{\mathrm{A}}\right)$ and reflection loss $\left(\mathrm{SE}_{\mathrm{R}}\right)$ components as shown in Fig. 13(b and c), respectively. The figure shows that $\mathrm{SE}_{\mathrm{R}}$ increases with the increase in MWCNT loading because of the increase in electrical conductivity of the composites (Fig. 13(d)). This also shows that with an increase in the a-MWCNT content, $\mathrm{SE}_{\mathrm{A}}$ increases more rapidly compared to the corresponding $\mathrm{SE}_{\mathrm{R}}$ component. Such a behavior is a direct consequence of the square root and the logarithmic dependence of $\mathrm{SE}_{\mathrm{A}}$ and $\mathrm{SE}_{\mathrm{R}}$ on conductivity, respectively. ${ }^{17,45}$ It was observed that the $\mathrm{SE}_{\mathrm{R}}$ component for PCNT10 was $7.5 \mathrm{~dB}$; however, the $\mathrm{SE}_{\mathrm{A}}$ component was $21.5 \mathrm{~dB}$. It can also be correlated with the skin depth of these composites.

The EM radiation of high frequencies penetrates only a thin region at the surface of electrically conducting materials. This is known as the skin effect. ${ }^{45-47}$ The depth at which the field drops to $1 / e$ of the incident value is called the skin depth $(\delta)$ which is represented by

$$
\delta=\left(\frac{2}{f \mu \sigma}\right)^{1 / 2}=-8.68\left(\frac{t}{\mathrm{SE}_{\mathrm{A}}}\right)
$$
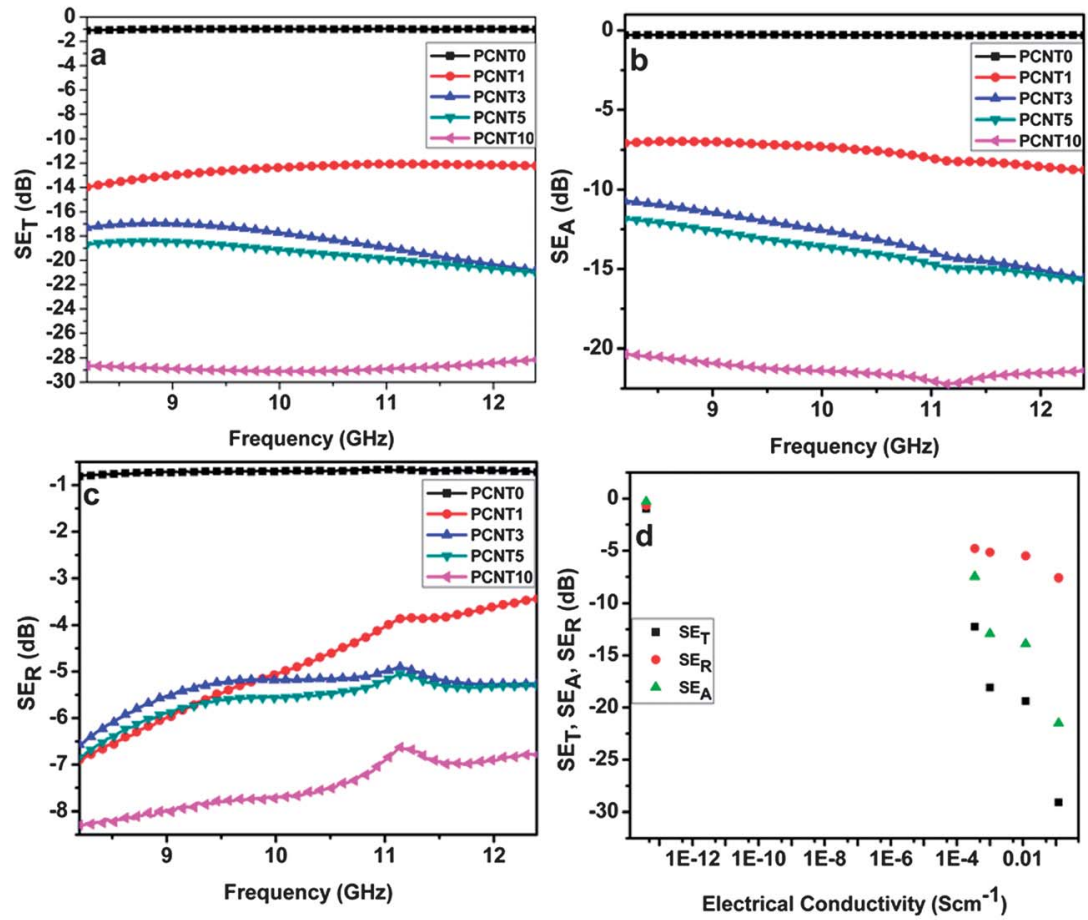

Fig. 13 Frequency dependent EMI shielding effectiveness of (a) $S E_{T}(T=A+R)$, (b) $S E_{A}$, and (c) $S E_{R}$. (d) Variation in the values of $S E_{T}, S E_{A}$ and $S E_{R}$ with electrical conductivity of a-MWCNT-PU composite films. 

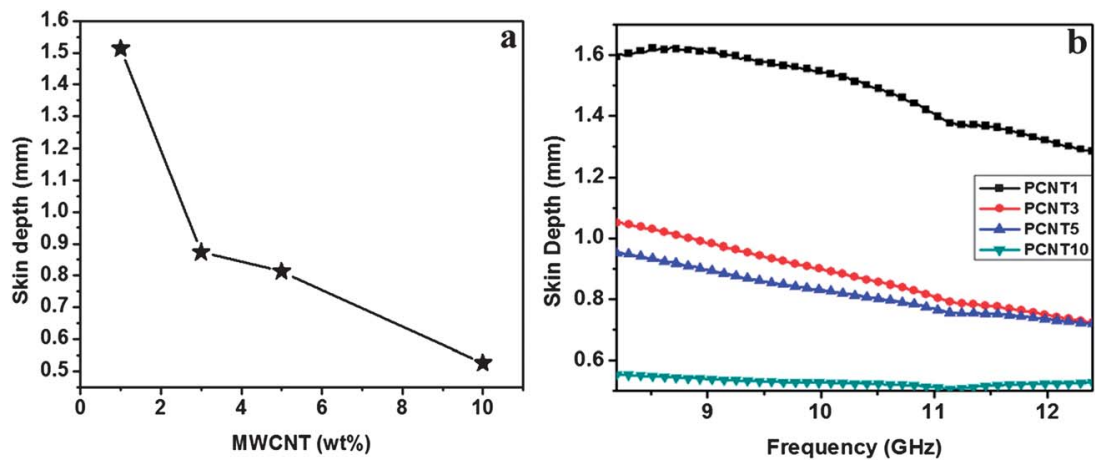

Fig. 14 Variation of skin depth of a-MWCNT-PU composites (a) with MWCNT loading and (b) frequency.

where $f$ is the frequency, $\sigma$ is the electrical conductivity, $\mu$ is the magnetic permeability and $t$ is the thickness of the material. Fig. 14(a and b) show the variation of skin depth with the increase in wt\% of MWCNT in the PU matrix and with the increase in frequency, respectively. It can be seen that the skin depth of the MWCNT-PU composite film decreases with the increase in the frequency and MWCNT loading. The decrease in the skin depth with the increase in frequency is responsible for the observed increase in absorption loss at higher frequency. The high electrical conductivity, low skin depth and large lattice defects in the CNTs (generated during functionalization i.e. existence of defects in MWCNTs) should help in enhancing the absorption capacity of microwave absorbing materials. ${ }^{46}$ Hence, PCNT10 shows an absorption dominated shielding $\left(\mathrm{SE}_{\mathrm{T}}\right)$ value of $-29 \mathrm{~dB}$ which is higher than the recommended acceptable limit $(-20$ to $-30 \mathrm{~dB})$ for commercial applications. ${ }^{45}$

Thus, in the present study, because of the use of functionalized MWCNTs, a large improvement in the nanoindentation properties (hardness and elastic modulus) of a-MWCNT-PU composites (with $10 \mathrm{wt} \% \mathrm{CNT}$ loading) was observed. In the previous study reported by Kucerova et al. ${ }^{28}$ the improvement in hardness was 1.4 times whereas, in the present study, 2.71 times improvement in hardness has been observed. The remarkable difference is due to the use of functionalized CNTs, which helps in the excellent dispersion and formation of hydrogen bonds between PU and CNT. To the best of our knowledge, the improvement in the nanoindentation properties (hardness and elastic modulus) reported in the present study for a-MWCNTPU composites is the highest.

\section{Conclusion}

MWCNT-PU composite films have been fabricated and significant enhancement in their mechanical, electrical and EMI shielding properties has been observed. An overall enhancement of $271 \%$ in the hardness and $290 \%$ in elastic modulus was observed in the nanoindentation test. The addition of MWCNTs into the PU matrix not only reduced the deformation energy considerably but also improved the stiffness and other mechanical parameters significantly. In addition to improved mechanical properties, the absorption dominating $\mathrm{SE}_{\mathrm{T}}$ reached upto $-29 \mathrm{~dB}$ with an $\mathrm{SE}_{\mathrm{A}}$ of $-21 \mathrm{~dB}$ in the $\mathrm{X}$-band $(8.2-12.4 \mathrm{GHz})$ frequency for $10 \mathrm{wt} \%$ loaded a-MWCNT-PU composites, which is the highest reported value to the best of our knowledge in the literature for MWCNT-PU composites in the X-band at $1.5 \mathrm{~mm}$ thickness. These films could find industrial applications as scratchless coatings in the automobile industry, EMI radiation shielding bags for packaging of electronic circuit boards, conducting tape for laminating electronic circuits, etc.

\section{Acknowledgements}

The authors are grateful to Prof. R. C. Budhani, Director, CSIRNational Physical Laboratory, New Delhi for his kind support and encouragement. The authors also wish to thank Dr O. S. Panwar and Dr Sree Kumar Chockaligam for nanoindentation measurements, Mr K. N. Sood and Mr Jai Tawale for SEM characterization, the conducting polymer group for EMI shielding measurements and $\mathrm{Mr}$ Dinesh Singh for the preparation of the sample for TEM. One of the authors, TKG, acknowledges CSIR, Govt. of India, for providing a senior research fellowship (SRF).

\section{References}

1 C. C. Yong Li, S. Zhang, Y. Ni and J. Huang, Appl. Surf. Sci., 2008, 254, 5766-5771.

2 B. S. Chhiu-Tsu Lin, M. Kolody, C. Sizemore and J. Bahns, Prog. Org. Coat., 2003, 47, 190-197.

3 G. B. Zunfeng Liu, Y. Huang, et al., Carbon, 2007, 45, 821827.

4 R. B. Mathur, S. Pande and B. P. Singh, Polymer Nanotube Nanocomposites: Synthesis, Properties, and Applications, 2010, vol. 11, p. 177.

5 D. D. L. Chung, Carbon, 2001, 39, 279-285.

6 N. Li, Y. Huang, F. Du, X. He, X. Lin, H. Gao, Y. Ma, F. Li, Y. Chen and P. C. Eklund, Nano Lett., 2006, 6, 1141-1145.

7 M. Arjmand, M. Mahmoodi, G. A. Gelves, S. Park and U. Sundararaj, Carbon, 2011, 49, 3430-3440.

8 Y. Yang, M. C. Gupta and K. L. Dudley, Nanotechnology, 2007, 18, 345701-345704.

9 M. H. Al-Saleh and U. Sundararaj, Carbon, 2009, 47, 2-22.

10 Y. Yang, M. C. Gupta, K. L. Dudley and R. W. Lawrence, Nano Lett., 2005, 5, 2131-2134. 
11 Y. Huang, N. Li, Y. Ma, D. Feng, F. Li, X. He, X. Lin and H. Gao, Carbon, 2007, 45, 1614-1621.

12 Y. Yang, M. C. Gupta, K. L. Dudley and R. W. Lawrence, J. Nanosci. Nanotechnol., 2005, 5, 927-931.

13 R. B. Mathur, S. Pande, B. P. Singh and T. L. Dhami, Polym. Compos., 2008, 29, 717-727.

14 S. Pande, B. P. Singh, R. B. Mathur, T. L. Dhami, P. Saini and S. K. Dhawan, Nanoscale Res. Lett., 2009, 4, 327-334.

15 H. M. Kim, K. Kim, C. Y. Lee, J. Joo, S. J. Cho, H. S. Yoon, D. A. Pejakovic, J. W. Yoo and A. J. Epstein, Appl. Phys. Lett., 2004, 84, 589-591.

16 S. M. Yuen, C. C. M. Ma, C. Y. Chuang, K. C. Yu, S. Y. Wu, C. C. Yang and M. H. Wei, Compos. Sci. Technol., 2008, 68, 963-968.

17 B. P. Singh, Prabha, P. Saini, T. Gupta, et al., J. Nanopart. Res., 2011, 13, 7065-7074.

18 M. H. Al-Saleh and U. Sundararaj, Carbon, 2009, 47, 17381746.

19 B. P. Singh, Praasnta, V. Choudhary, P. Saini, S. Pande, V. N. Singh and R. B. Mathur, J. Nanopart. Res., 2013, 15, 1-12.

20 B. P. Singh, P. Bharadwaj, V. Choudhary and R. B. Mathur, Appl. Nanosci., 2013, 1-8, DOI: 10.1007/s13204-013-0214-0.

21 C. Hepburn, Polyurethane Elastomers, Elsevier, Essex, 1992, vol. 1.

22 G. S. Rev, Colloid Polym. Sci., 1989, 267, 757-785.

23 H. Xia and M. Song, Soft Matter, 2005, 1, 386-394.

24 C. Hepburn, Polyurethane Elastomers, Applied Science Publishers, London, 1982.

25 Z. Liu, G. Bai, Y. Huang, et al., J. Phys. Chem. C, 2007, 111, 13696-13700.

26 A. S. Hoang, Adv. Nat. Sci.: Nanosci. Nanotechnol., 2011, 2, 1-5.

27 W. C. Oliver and G. M. Pharr, J. Mater. Res., 1992, 7, 1564-1583.

28 Z. Kučerová, L. Zajíčková, V. Buršíková, V. Kudrle, M. Eliáš,

O. Jašek, P. Synek, J. Matějková and J. Buršík, Micron, 2009, 40, 70-73.
29 R. B. Mathur, S. Chatterjee and B. P. Singh, Compos. Sci. Technol., 2008, 68, 1608-1615.

30 S. Pande, R. B. Mathur, B. P. Singh and T. L. Dhami, Polym. Compos., 2008, 30, 1312-1317.

31 B. P. Singh, D. Singh, R. B. Mathur and T. L. Dhami, Nanoscale Res. Lett., 2008, 3, 444-453.

32 N. Dwivedi, S. Kumar, C. M. S. Rauthan and O. S. Panwar, Appl. Phys. A: Mater. Sci. Process., 2011, 102, 225-230.

33 N. Dwivedi, S. Kumar and H. K. Malik, Appl. Surf. Sci., 2011, 257, 9953-9959.

34 N. Panich and S. Yong, KMITL Sci. J., 2005, 5, 483-492.

35 M. Lucas and R. J. Young, Compos. Sci. Technol., 2004, 64, 2297-2302.

36 D. A. Heller, P. W. Barone, J. P. Swanson, R. M. Mayrhofer and M. S. Strano, J. Phys. Chem. B, 2004, 108, 6905-6909.

37 H. Xia and M. Song, Soft Matter, 2005, 1, 386-394.

38 S. Parnell, K. Min and M. Cakmak, Polymer, 2003, 44, 51375144.

39 G. Cassanas, G. Kister, E. Fabrègue, M. Morssli and L. Bardet, Spectrochim. Acta, Part A, 1993, 49, 271-279.

40 G. Kister, G. Cassanas, E. Fabrègue and L. Bardet, Eur. Polym. J., 1992, 28, 1273-1277.

41 W. J. O.-T., J. Mol. Struct., 1974, 23, 477-478.

42 C. A. Charitidis, Int. J. Refract. Met. Hard Mater., 2010, 20, 51-70.

43 Y. Wang and X. Jing, Polym. Adv. Technol., 2005, 16, 344351.

44 P. Saini, V. Choudhary, B. P. Singh, R. B. Mathur and S. K. Dhawan, Mater. Chem. Phys., 2009, 113, 919-926.

45 P. Saini, V. Choudhary, B. P. Singh, R. B. Mathur and S. K. Dhawan, Synth. Met., 2011, 161, 1522-1526.

46 R. Kumar, S. R. Dhakate, T. Gupta, P. Saini, B. P. Singh and R. B. Mathur, J. Mater. Chem. A, 2013, 1, 5727-5735.

47 B. P. Singh, V. Choudhary, P. Saini and R. B. Mathur, AIP Adv., 2012, 2, 022151-022156. 